\title{
Two grave issues concerning the expected Tokai Earthquake
}

\author{
Kiyoo Mogi \\ University of Tokyo, Japan \\ (Received November 7, 2003; Revised June 29, 2004; Accepted June 30, 2004)
}

\begin{abstract}
The possibility of a great shallow earthquake (M 8) in the Tokai region, central Honshu, in the near future was pointed out by Mogi in 1969 and by the Coordinating Committee for Earthquake Prediction (CCEP), Japan (1970). In 1978, the government enacted the Large-Scale Earthquake Countermeasures Law and began to set up intensified observations in this region for short-term prediction of the expected Tokai earthquake. In this paper, two serious issues are pointed out, which may contribute to catastrophic effects in connection with the Tokai earthquake: 1. The danger of black-and-white predictions: According to the scenario based on the Large-Scale Earthquake Countermeasures Law, if abnormal crustal changes are observed, the Earthquake Assessment Committee (EAC) will determine whether or not there is an imminent danger. The findings are reported to the Prime Minister who decides whether to issue an official warning statement. Administrative policy clearly stipulates the measures to be taken in response to such a warning, and because the law presupposes the ability to predict a large earthquake accurately, there are drastic measures appropriate to the situation. The Tokai region is a densely populated region with high social and economic activity, and it is traversed by several vital transportation arteries. When a warning statement is issued, all transportation is to be halted. The Tokyo capital region would be cut off from the Nagoya and Osaka regions, and there would be a great impact on all of Japan. I (the former chairman of EAC) maintained that in view of the variety and complexity of precursory phenomena, it was inadvisable to attempt a black-and-white judgment as the basis for a "warning statement". I urged that the government adopt a "soft warning" system that acknowledges the uncertainty factor and that countermeasures be designed with that uncertainty in mind. 2. The danger of nuclear power plants in the focal region: Although the possibility of the occurrence of a great shallow earthquake in the Tokai region was pointed out by CCEP in 1970, soon after, plans for construction of a nuclear power plant started in this region. Since 1976, Hamaoka nuclear power plants (Units 1 4) have been operating near the center of the expected focal region of the great Tokai earthquake, and Unit 5 is under construction. This is quite a dangerous situation.
\end{abstract}

Key words: Tokai, Earthquake Countermeasures Law, precursory phenomena, black-and-white prediction, soft warning, Hamaoka nuclear power plant, man-made disaster.

\section{Origin and Progress of the "Tokai Earthquake" Problem}

The Tokai region, in central Honshu, Japan is the sole target of the Large-Scale Earthquake Countermeasures Act. The possibility of the future occurrence of a great shallow earthquake in the Tokai region was pointed out by Mogi (1970, oral presentation, 1969; also see Utsu, 1999) based on the horizontal crustal deformation (Harada and Isawa, 1969) and seismic gap hypothesis. Chronology of the early stages of development of the expected Tokai earthquake problem is summarized in Table 1. In 1970, the Tokai region was designated as an Area of Specific Observation for a M8 earthquake by the Coordinating Committee for Earthquake Prediction (CCEP). In 1974, the region was upgraded to an Area of Intensified Observation. In 1976, Ishibashi (1976) proposed a model consisting of a large thrust event along the Suruga trough. In 1978, the government enacted the Large-Scale Earthquake Countermeasures Law and began implementing measures to prepare for the earthquake. Also

Copy right (C) The Society of Geomagnetism and Earth, Planetary and Space Sciences (SGEPSS); The Seismological Society of Japan; The Volcanological Society of Japan; The Geodetic Society of Japan; The Japanese Society for Planetary Sciences; TERRAPUB. in 1978, CCEP reexamined the designation of the Area of Intensified Observation and Area of Specific Observation. The designation of special regions in 1970 and 1978 is shown in Fig. 1. In what follows, some of these topics are explained in more detail.

Figure 2 shows the horizontal displacement vectors of the triangulation points of the Japanese Islands (except for Hokkaido) for 60 years (from 1883 to 1909 and from 1948 to 1967), as reported by Harada and Isawa (1969) on the basis of data from the Geographical Survey Institute (GSI). Mogi (1970) interpreted these results from a plate tectonics point of view, indicating how strain has accumulated in the Japanese Islands. The displacement vectors of the triangulation points are divided into components that are normal and parallel to the Nankai Trough, which is the subduction plate boundary. Looking at the normal components, some regions have been compressed toward the inland direction, and conversely, other regions have moved outward toward the sea side. Regions that have moved outward toward the sea are places where compressive strain has been released through the rebound caused by great thrust-type earthquakes along the trench. Regions that had marked displacements toward the inland side are places where compressive strain 


\section{Designation by the Coordinatig Committee for Earthquake Prediction}

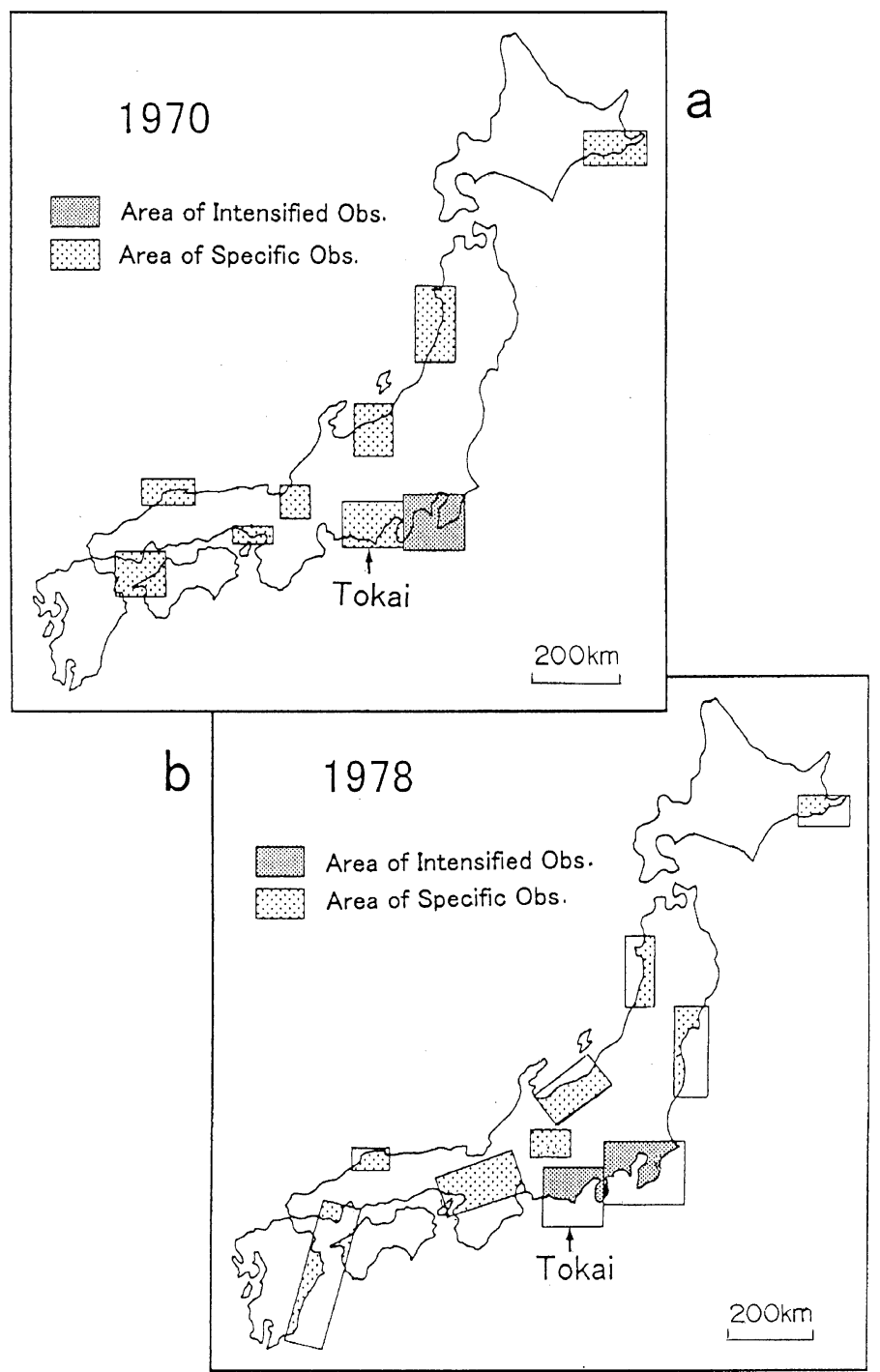

Fig. 1. Areas of Intensified Observation and Areas of Specific Observation designated by the Coordinating Committee for Earthquake Prediction in 1970 (top figure) and the revised one in 1978 (bottom).

Table 1. Tokai earthquake problem.

\begin{tabular}{|cl|}
\hline 1969 & $\begin{array}{l}\text { Horizontal crustal deformation in Japan (Harada and Isawa) } \\
\text { Possibility of "Tokai earthquake" (Mogi) }\end{array}$ \\
1970 & $\begin{array}{l}\text { Designation by the Coordinatig Committee for Earthquake Prediction (CCEP) } \\
\text { "Area of Specific Observation" }\end{array}$ \\
1974 & "Area of Intensified Observation" (CCEP) \\
1976 & Focal model (Ishibashi) \\
1978 & "Large-Scale Earthquake Countermeasures Law" \\
1979 & "Areas Under Intensified Measures Against Earthquake Disasters" \\
& Earthquake Assessment Committee \\
& (Central Disaster Management Council)
\end{tabular}

has been accumulated and are viewed as potential sites for a great earthquake. Figure 3 (top) shows the distribution of the magnitude of the displacement components normal to the trend of the Nankai Trough. The lower figure shows loca- tions of focal regions of three great thrust-type earthquakes, 1923 Kanto earthquake (M 7.9), 1944 Tonankai earthquake (M 7.9) and 1946 Nankai earthquake (M 8.0), which occurred along the Nankai-Sagami Trough during the above- 


\section{Displacement Vectors of Triangulation Points}

$$
(1883-1904) \sim(1948-1964)
$$

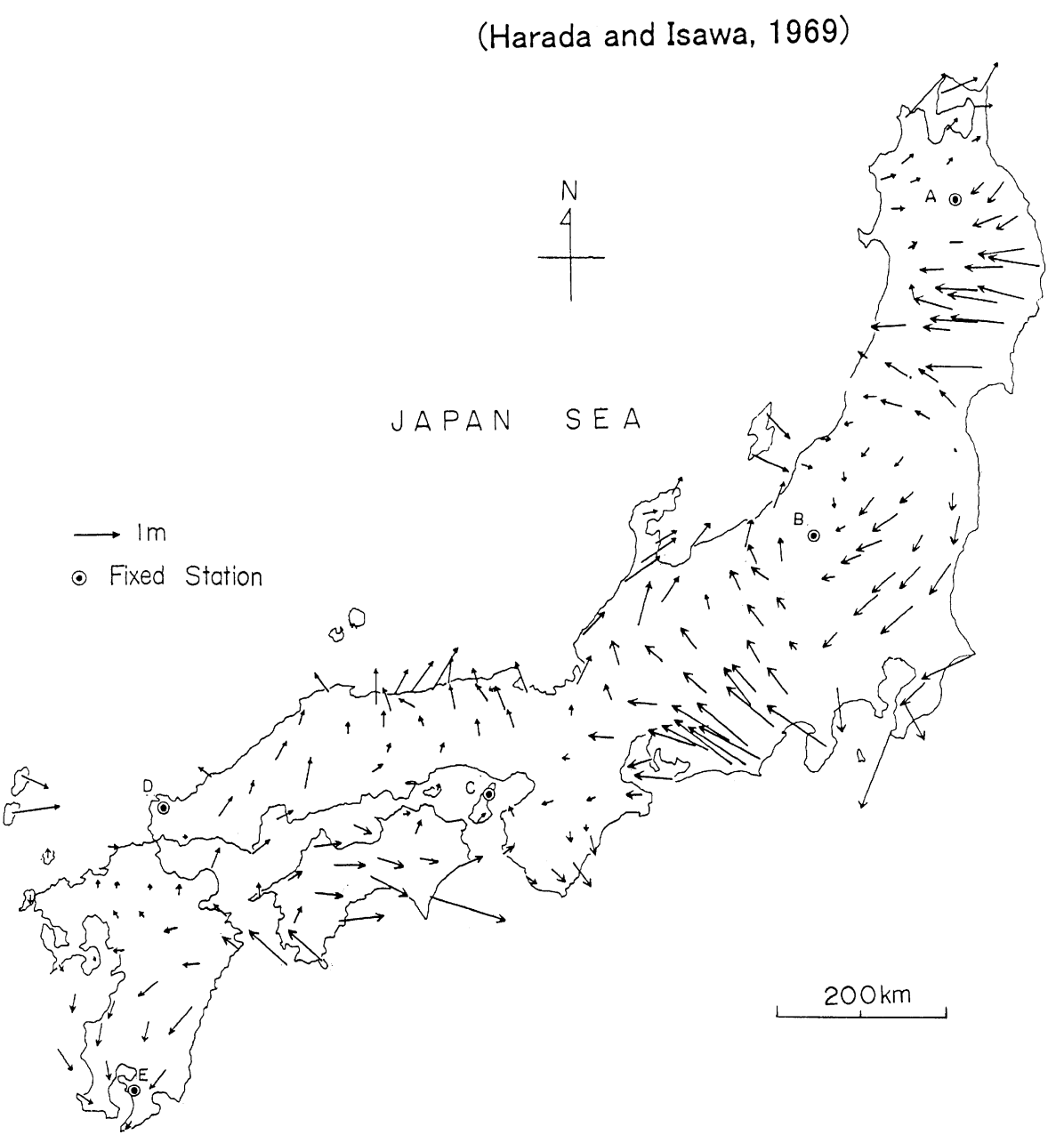

Fig. 2. Horizontal displacement vectors of the triangulation points of the Japanese islands (except for Hokkaido) for 60 years (from 1883 to 1909 and from 1948 to 1967) obtained by multiple fixed stations method by Harada and Isawa (1969). Solid double circles show fixed station (A $\sim$ E).

mentioned 60 years. It is noted that no great earthquakes occurred in the Tokai region, and this region remains as an un-ruptured region (the last rupture of this region occurred in 1854). Focusing on the horizontal crustal movements and this seismic gap of the first kind, Mogi (1970) pointed out the possibility of a great earthquake occurring in the Tokai region.

Harada and Isawa (1969) analyzed the triangulation data under the assumption that five stations chosen in stable regions considered to have no displacement. The five fixed stations are indicated by closed double circles in Fig. 2. In order to verify the pattern of deformation, Kasahara and Sugimura (1964) calculated the distribution of horizontal strain in the western Japan, since the strain analysis does not contain any assumptions about fixed stations. Figure 4 shows the spatial distributions of compression or extension in the direction normal to the trend of the Nankai Trough (Mogi, 1970), which was modified from the original figure by Kasahara and Sugimura (1964). Solid circles show the observations in which the direction of the maximum compression axes are nearly normal to the trend of the Nankai Trough. The spatial pattern of strain in the direction normal to the trend of the Nankai Trough is quite similar in Fig. 3 and Fig. 4, thus, supporting the reliability of Fig. 3 .

Recently the methods for measurements of horizontal displacements of the earth's surface have been improved drastically by application of the Global Positioning System (GPS). Figure 5 shows horizontal displacements observed by GPS during recent two years period (1998-1999) in and around the Tokai region. It is noticeable that this horizontal displacement pattern in and around the Tokai region is nearly similar to that in Fig. 2.

In 2001, the Central Disaster Management Council reported a modified source region of the expected Tokai earthquake and the expected Seismic Intensity associated with the occurrence of the earthquake (Fig. 6). This source model was estimated from various data including crustal deformations, seismic activity, and submarine topography (Central Disaster 


\section{Horizontal Displacements Normal to the}

\section{Trend of Nankai Trough}

(Mogi, 1970)
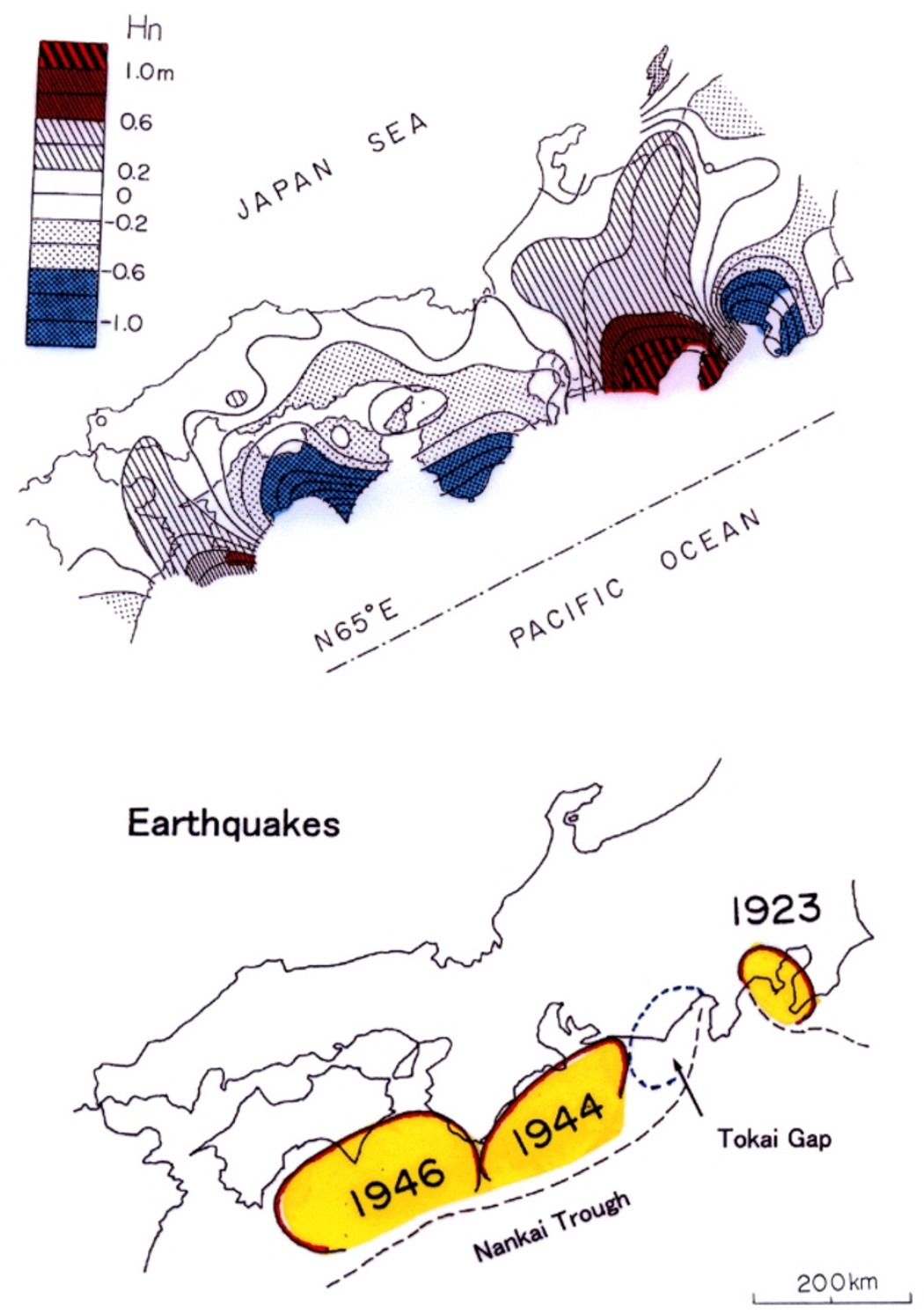

Fig. 3. Distribution of the magnitude (Hn) of the horizontal displacement, components normal to the trend of the Nankai Trough (top). The bottom figure shows locations of focal regions of three great thrust-type earthquakes, which occurred along the Nankai-Suruga Trough during the above-mentioned 60 years. The Tokai region is recognized as a seismic gap of the first kind (modified Mogi, 1970).

Management Council, 2001).

\section{Danger of Black-and-White Predictions}

From 1991, I was appointed as the chairman of the Earthquake Assessment Committee for the expected Tokai earthquake. I maintained that in view of the variety and complexity of precursory phenomena, it was inadvisable to attempt a black-or-white judgment regarding the likelihood of an imminent earthquake and to use such a judgment as the basis for a "warning statement" created a situation equivalent to martial law. In order for the public to act accordingly to earthquake, they must be also informed about the levels of uncertainty. I have urged that the government adopt a "soft warning" system that acknowledges the uncertainty factor and that countermeasures be designed with that uncer- tainty in mind. Unfortunately, at that time there was no sign of progress with regards to this problem, and in 1996 I resigned my post. More recently, it seems, people have begun to recognize the seriousness of the problem, and the issue has finally come under serious discussion in Japan.

\subsection{High cost of false alarms}

As mentioned before, in 1970, CCEP pointed out the likelihood of an M8 earthquake in the Tokai district. The region was designated as an "Area of Specified Observation," and in 1974 the designation was upgraded to an "Area of Intensified Observation.” In 1976, a report by Ishibashi (1976) received widespread coverage in the media, which gave rise to considerable anxiety among the residents of the region, centered on Shizuoka Prefecture.

The government enacted the Large-Scale Earthquake 


\title{
Distribution of Strain Normal to the Trend of Nankai Trough
}

\author{
Obtained from Kasahara and Sugimura (1964)
}

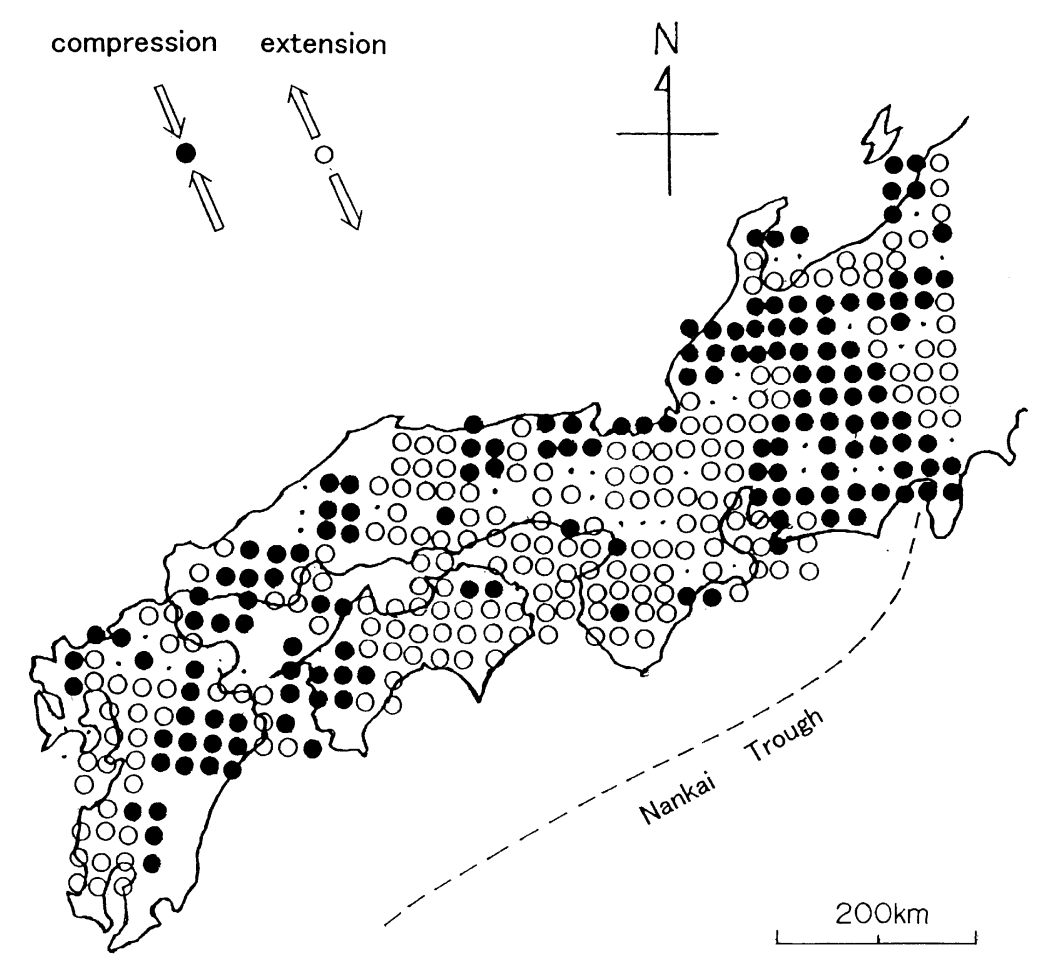

Fig. 4. Distribution of strain (compression or extension) in the direction normal to the trend of the Nankai Trough (Mogi, 1970). This graph was obtained from the horizontal strain calculated by Kasahara and Sugimura (1964).

Countermeasure Law and began implementing measures to prepare for the earthquake. The law was enacted on the supposition that a major earthquake of the size of the expected Tokai earthquake can be predicted because unmistakable precursory phenomena will be observed over a relatively wide area.

This scenario calls for data gathered at observation stations throughout the Tokai district to be relayed to the Japan Meteorological Agency (JMA) by modern telemetry, where they will be continuously monitored. If something out of the ordinary is observed, the Earthquake Assessment Committee (EAC), a private advisory panel to the director general of JMA, will be convened and make a determination regarding the likelihood of a major earthquake. If the EAC determines that there is an imminent danger, it will relay this information to the director general of JMA. Assuming the director general agrees with the recommendation, the findings will then be reported to the Prime Minister, who will convene a cabinet meeting and decide whether to issue an official "warning statement."

Administrative policy also clearly stipulates measures to be taken in response to such a warning. Because the law presupposes the ability to predict a great earthquake with accuracy, there are drastic measures appropriate to a situation in which it is believed that an earthquake is almost certain to strike at any moment.

The Tokai region is a densely populated region with high social and economic activities. Located between Tokyo and Osaka, it is traversed by several vital transportation arteries: The Tokaido Shinkansen "bullet train" line, the Tokaido Expressway, and the Chuo Expressway.

When a warning statement is issued, all transportation along the Shinkansen and expressways within the areas of intensified disaster measures are to be halted. Banks, post offices, department stores, and supermarkets would also close. Hospitals would suspend out-patient treatment, and all children would be sent home from school. The response measures in the Tokai area when a warning statement is issued are summarized in Table 2 with some simplification. These are measures comparable to those taken under martial law. The capital region would be cut off from Nagoya and Osaka, the country's central and western centers of population and commerce, and the impact would be felt in all of Japan (Fig. 7).

A warning may continue for several days, but it is unlikely that the Japanese could function under such severe restrictions for more than a few days.

\subsection{Need for intermediate warning levels}

At a 1987 symposium on earthquake prediction research jointly sponsored by the Science Council of Japan and the Seismological Society of Japan, I pointed out the difficulty of dealing with earthquake hazards solely on the basis of a simple yes-or-no, black-or-white prediction, and called for the adoption of intermediate "gray" warnings (Mogi, 1987). 


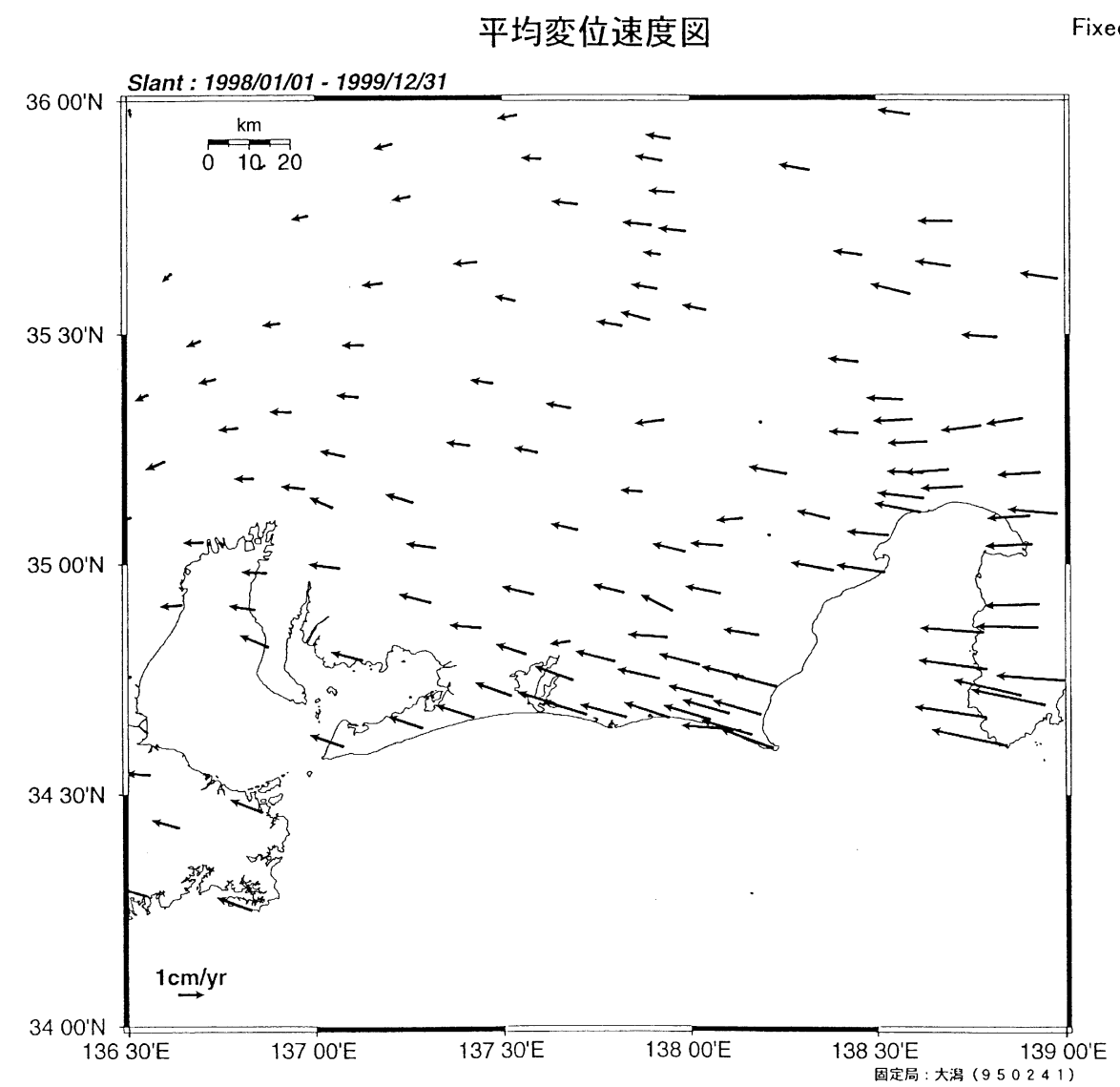

Fig. 5. Horizontal displacements observed by GPS (1998-1999) in and around the Tokai region (after Geographical Survey Institute, Japan, 2003).

Table 2. Measures to be taken in the Tokai Area, when a Warning Statement is issued.

\begin{tabular}{|c|c|}
\hline Railways & Stopping of cars. Prohibition of inflow from outside areas. \\
\hline Road Traffic & Prohibition of inflow from outside areas. \\
\hline Bank/Post Offices & Stopping of all operations. \\
\hline $\left.\begin{array}{l}\text { Department Stores } \\
\text { Supper Markets }\end{array}\right\}$ & Closing. \\
\hline Hospitals & Stopping of operation for outpatients. \\
\hline Schools & Children send back home. \\
\hline
\end{tabular}

(Simplified Land Agency, 1987)

My reasons can be summarized as follows.

First, if we study past earthquakes, we find very few instances in which the earthquake was preceded by unmistakable precursors. Where precursory phenomena were observed by instruments, they were most often not clear. To make earthquake prediction useful, we need to focus on these weak precursory changes.

Second, there has been no reliable recorded instance of a Tokai earthquake which occurred in isolation in the area bounded by Suruga Bay and Enshu-nada (Sea of Enshu), as expected this time. When this region has ruptured in the past, it has always been part of larger earthquakes that included a greater area along the Nankai Trough. The great 1854 Tokai earthquake occurred across the whole region from the Tokai district to the Kii Peninsula south of Osaka along NankaiSuruga Trough. Accordingly, we have no experience on what sort of precursory phenomena may precede a Tokai earthquake that ruptures only this smaller region. Data from leveling surveys just before the 1944 Tonankai earthquake off the southeast coast of the Kii Peninsula might have provided useful hints (Mogi, 1985), but the focal region is different from that of the expected Tokai earthquake and these leveling data were limited. The prediction of a Tokai earthquake is thus a first-time undertaking in an area for which we have no prior data. Moreover, since a fairly large part of the expected focal region is located under the ocean, the monitor- 
Expected Tokai Earthquake $=$ Focal Region and Seismic Intensity

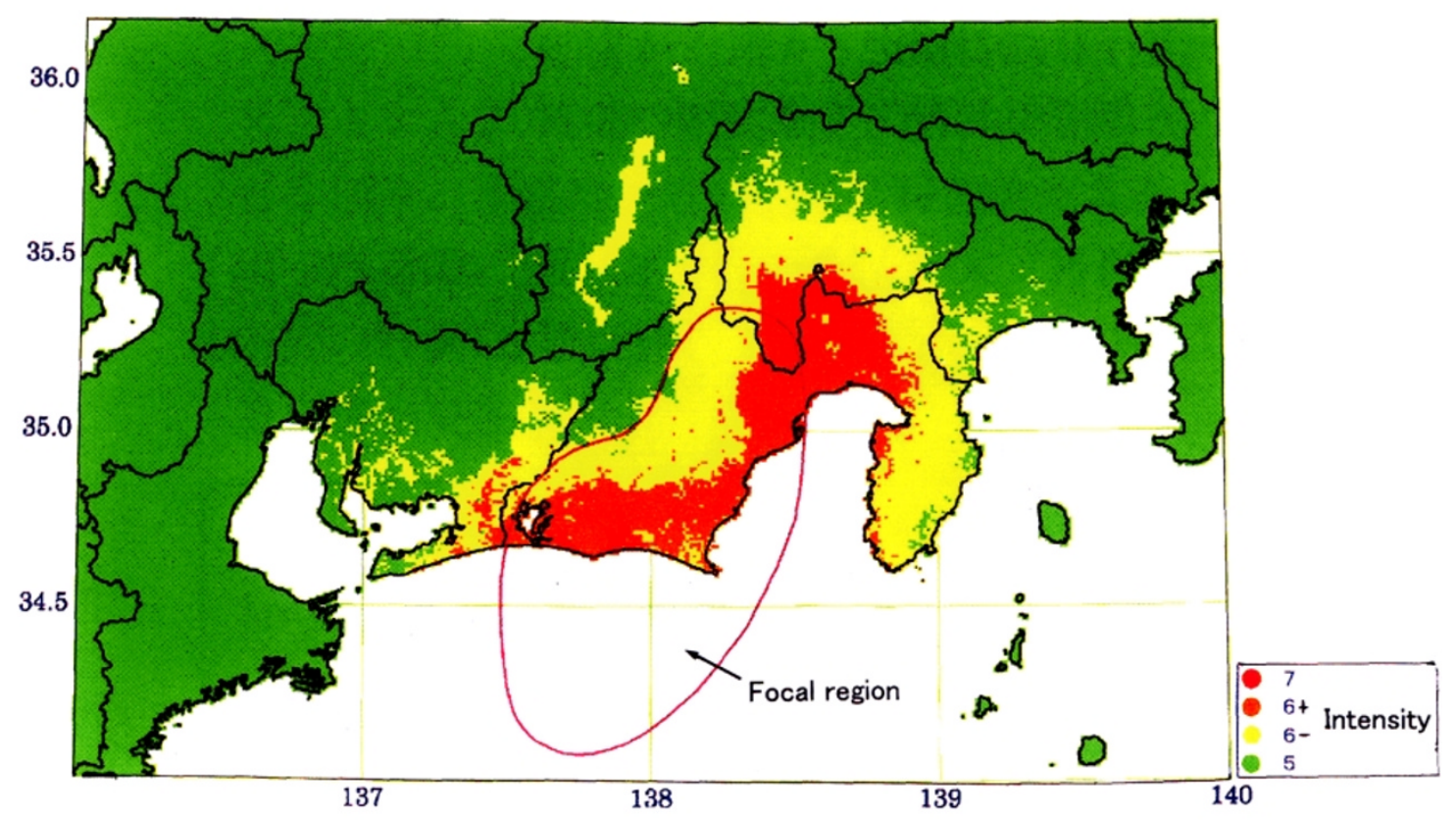

Central Disaster Management Council

Fig. 6. A modified source region of the expected Tokai earthquake (red curve) and the expected Seismic Intensity associated with the occurrence of the earthquake (Central Disaster Management Council, 2001).

\section{Areas for Intensified Earthquake Prevention Measures \\ Concerning the Expected Tokai Earthquake}

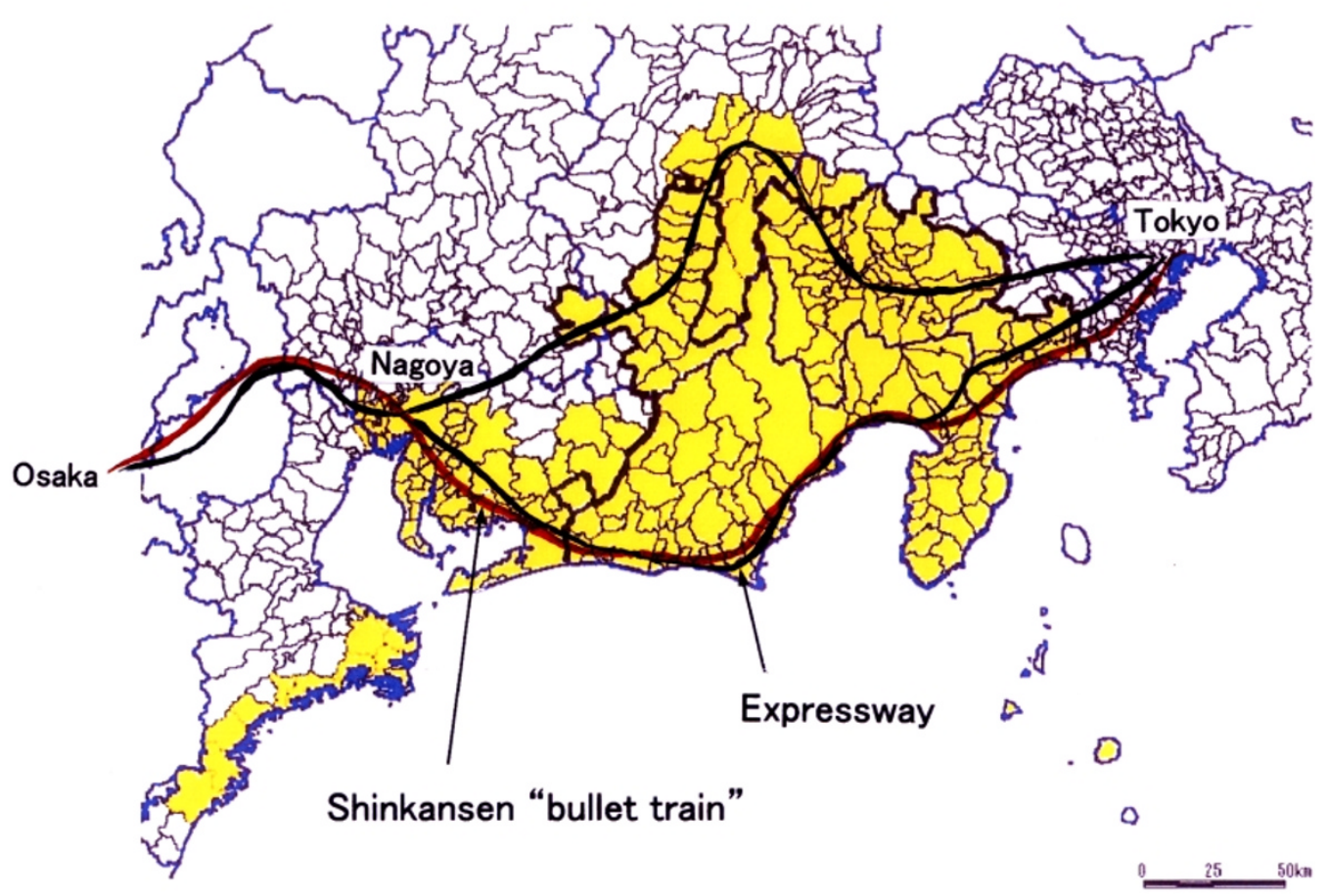

Fig. 7. Areas for Intensified Earthquake Prevention Measures Concerning the Expected Tokai Earthquake, designated by Central Disaster Management Council in 2002 (yellow region). The Tokaido Shinkansen "bullet train" line, the Tokaido Expressway, and the Chuo Expressway are also shown. 


\section{Variety and Complexity of Precursory Phenomena}

Large Earthquake

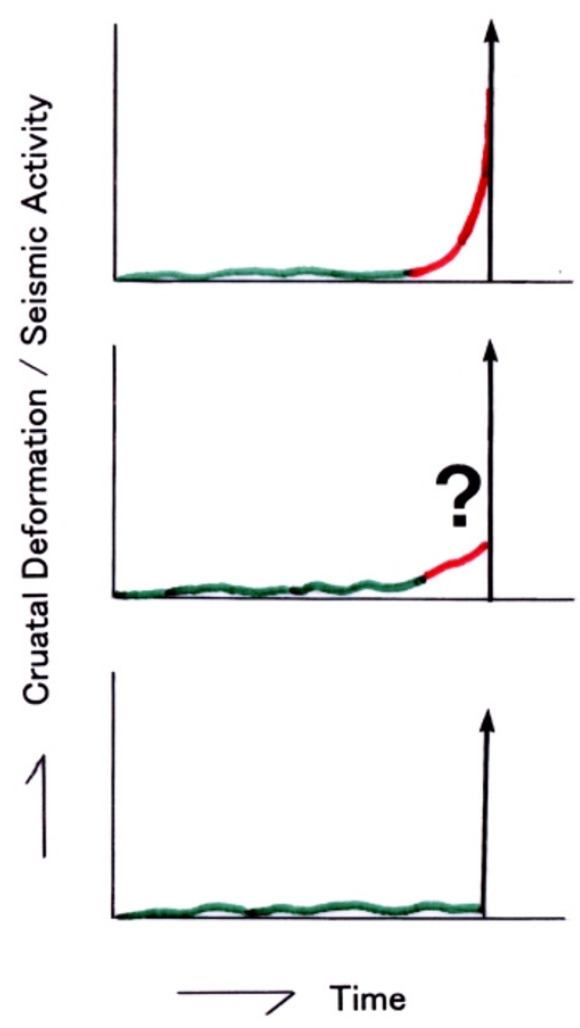

\author{
No Large Earthquake
}

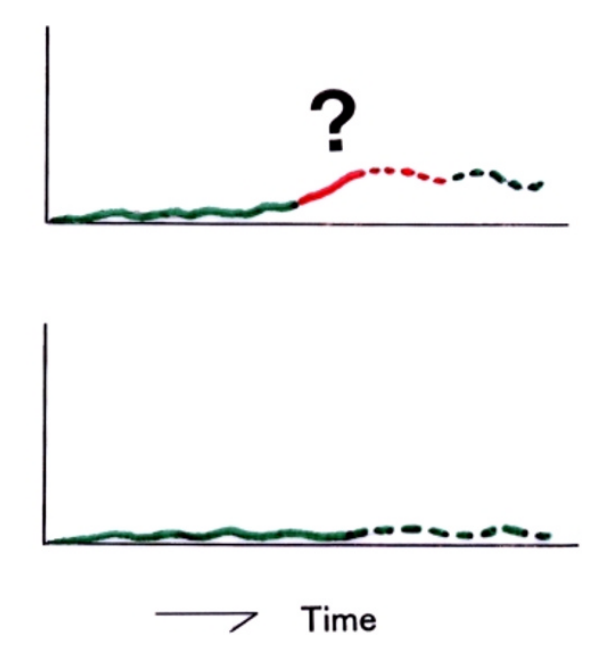

Fig. 8. A variety and complexity of precursory phenomena are schematically shown. The left figures show the possible development of crustal deformation or seismic activity for cases in which a large earthquake occurs. The right figure shows those for cases where no large earthquake occurs. For the middle case, a clear judgment may be difficult.

ing network is insufficient to observe all pertinent precursory phenomena.

According to our experience, a variety and complexity of precursory phenomena are schematically shown in Fig. 8. The figures on the left show the possible development of crustal deformation or seismic activity for cases in which a large earthquake occurs. The figure on the right shows those for cases where no large earthquake occurs. For the middle case on the left, a clear judgment may be difficult.

Under such circumstances, an all-or-nothing prediction and warning system makes no sense for a highly populated, heavily traveled area like the Tokai district. In the event that very pronounced anomalies were observed and interpreted unequivocally by experts, particularly those in the EAC, as precursors of the Tokai earthquake, an official warning statement could be issued. But in cases where less clear-cut anomalies occurred, that nonetheless concerned earthquake experts, it would make sense to issue a mild warning.

The basic status adopted under the Earthquake Countermeasures Law is to not disregard any anomaly that may portend an earthquake. This being the case, officials might well feel compelled to issue a warning statement in instances where they would be better advised to simply caution the public. With a warning statement, however, the probability of a false alarm would be high. On the other hand, given the high social and economic cost of a false alarm, officials might hesitate to issue a warning until the signs were unmistakable. Such hesitation would increase the probability of the earthquake occurrence without any kind of official warning.

To avoid both of these undesirable scenarios, it is necessary to offer more warning options, not simply the all-ornothing choice currently provided. Even weather forecasters report the probability of precipitation-be it 30\%, 50\%, etc.-instead of simply predicting rain or no rain. Weather forecasters have a great deal on which to base their predictions, including cloud movements recorded by the Himawari weather satellite and a wealth of day-to-day experience. Nonetheless, we all know that predicting the weather is no easy matter. Earthquakes, which are fracture phenomena at regions within the earth, are much more obscure. Compared to short-term earthquake prediction, there has been more success in developing methods for probabilistic long-term earthquake forecasts. Using geological fault slip rates, historical seismicity rates, and local crustal deformation rates, models can be developed to predict average earthquake occurrences in a region over a long time period (hundreds to thousands of years). These occurrence rates can be translated into probabilistic predictions of earthquake occurrence (e.g. Working 


\section{Distribution of Nuclear Power Plants (2001)}

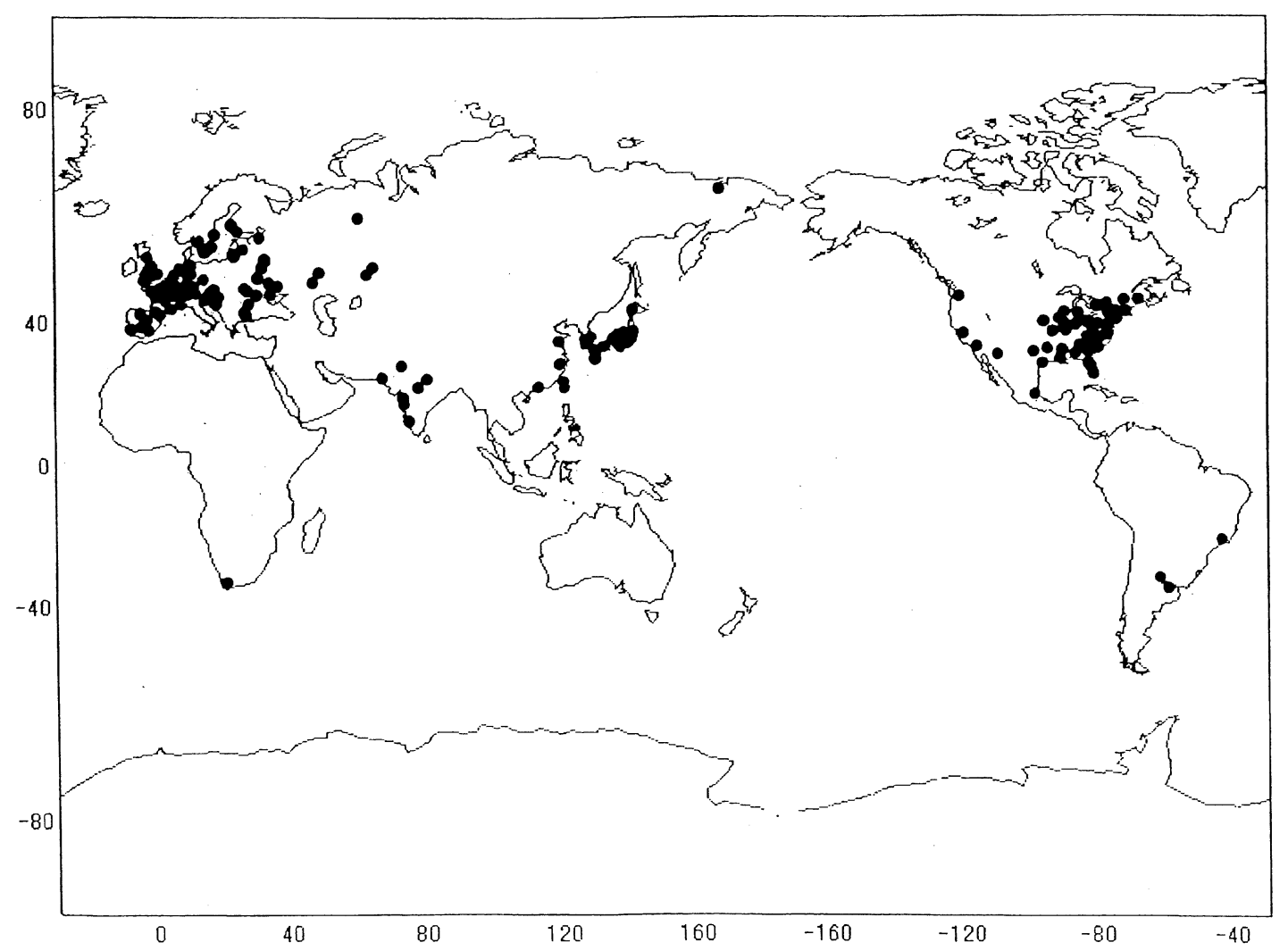

Fig. 9. Distribution of nuclear power plants in the world operated in 2001.

Table 3. A proposal of a mild warning system. Present system: Black-and-white prediction. Mild warning system: Black-gray-and-white prediction.

\begin{tabular}{|l|l|l|}
\hline & Black & Gray \\
\hline Train & Stop & Going slowly \\
Road Traffic & Stop & Going slowly \\
Bank & Operation stop & Normally \\
Hospital & Stop (patients out) & Normally \\
School & Back home & Normally \\
\hline Social and Economic cost & Very high & Low \\
\hline
\end{tabular}

Group on California Earthquake Probabilities, 1995). Although this methodology does not predict the occurrence of any particular earthquake, it does show how probabilistic analyses can provide useful information about damaging earthquakes over a longer time period.

For short-term predictions, scientists are asked to determine the size, place, and time of an earthquake on the basis of subtle signals scarcely detectable on the surface of the earth, before such fractures occur deep beneath the surface. In view of the difficulty of the task and the high cost of a false alarm, it makes no sense to force forecasters to choose either $0 \%$ or $100 \%$ probability. This is why we need milder warnings accompanied by less severe restrictions on social and economic activity.

\subsection{Benefits of a mild warning}

My own view is that the measures accompanying a caution or mild warning should involve slowing down rather than halting traffic on the Shinkansen and expressways also leaving hospitals, banks, post offices, and department stores open. The government should provide the people with the information they need to reduce potential damage, but keep disruption of their daily lives to a minimum. It is vital, however, that the measures to be taken by communities in response to such a warning be decided in advance, under the leadership of the government's crisis managers, and that they are executed smoothly and competently. If forecasters believe an earthquake may be imminent, a great deal of damage can be prevented simply by regulating transportation and advising residents to prepare calmly, within the context of their daily activities. For example, securing furniture and keeping gas stoppers closed can significantly reduce damage and fires if strong earthquake shaking occurs. Under these circumstances the cost of a false alarm will be minimal compared with that incurred by a warning statement. 


\section{Large Shallow Earthquakes in the Past 100 Years}

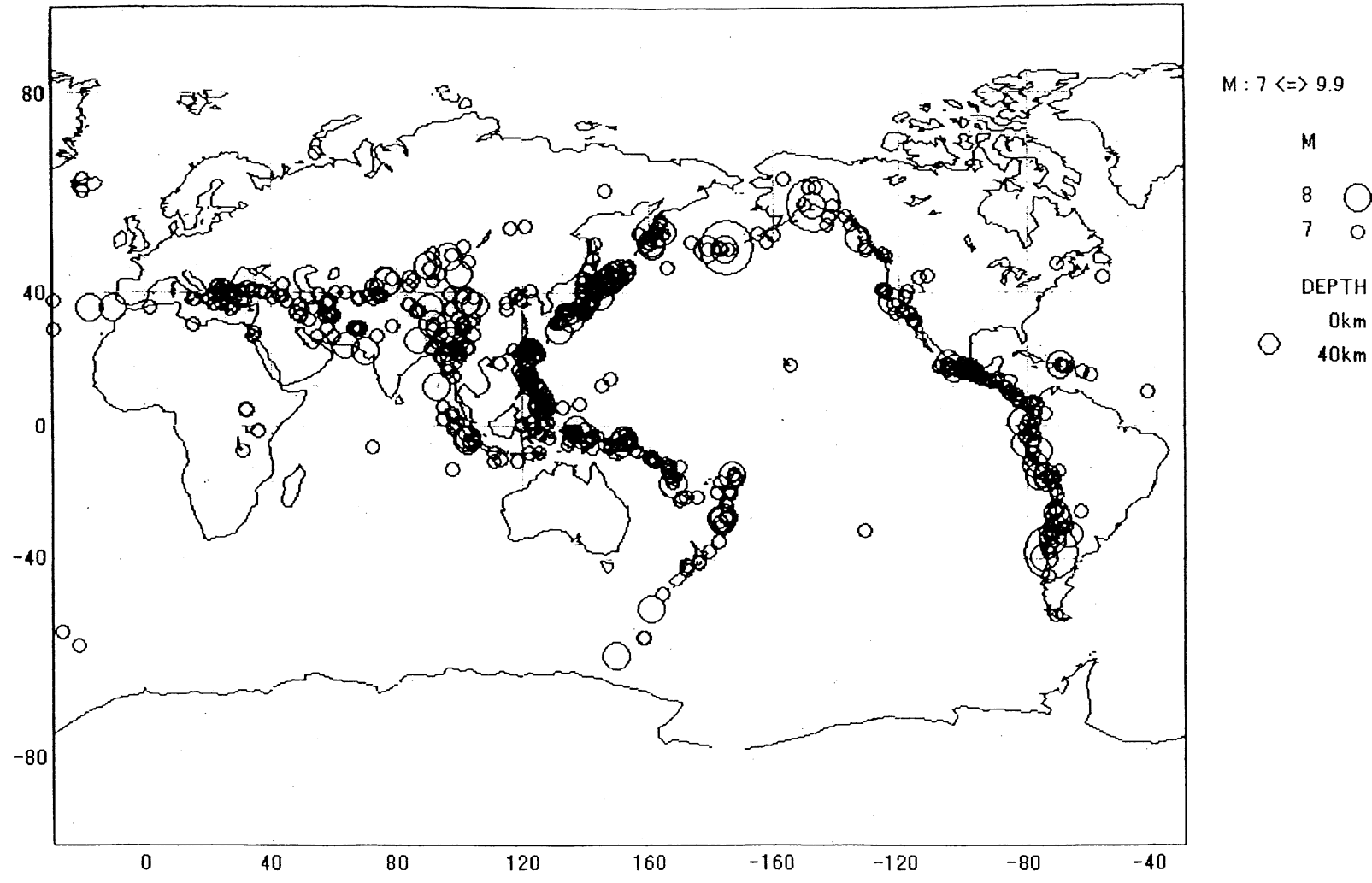

(Data from Utsu catalogue)

Fig. 10. Distribution of large shallow earthquakes of magnitude (M) 7.0 or larger with focal depths less than $40 \mathrm{~km}$ in the world that occurred in the past 100 years.

During the two decades since the Earthquake Countermeasures Law was enacted, major changes have occurred in society and in the science of seismology. It is curious that government policy for mitigating the hazards of the Tokai earthquake has been virtually exempt from debate simply because it is the basis of the Earthquake Countermeasures Law. The time has come for a thorough review of that policy, including the problem areas I have pointed out.

My resignation as chair of EAC appears to have alerted many people to the warning issue. Many say they had no idea there were such serious defects in the government's policy for dealing with the major Tokai earthquake. They wonder why such an obvious proposal has not been readily embraced. On the other hand, others have criticized my stance, maintaining that a scientist should speak only on scientific matters and not meddle in administrative affairs. Still, it is not appropriate for EAC to report its decision within a framework unsuited to the reality of the situation and then leave the rest to administrators with no specialized knowledge of earthquakes. We have a responsibility to join with administrators in considering the impact of our predictions and warnings.

\subsection{Recent movement}

In March 1996, since there was no move for reconsideration in spite of such a critical situation, I resigned as the chairman of EAC. I wanted to appeal this matter to the so- ciety in a visible manner. As a result, many people came to pay attention to this "mild warning issue" with the help of wide coverage by the media.

However, relevant agencies such as JMA continued in their current policies without any alternation of their thoughts. For example, they said "Chairman Mogi recommend that a soft warning system should be established, but it is not possible. The administration should not make any move unless we know the status of the situation in black or white" (e.g. Asahi Newspaper, Sept. 1, 1994).

I continued to emphasize the importance of this issue in my books and magazines (Mogi, 1996, 1998, 2001a, b). In addition, as an editorial writer for a Shizuoka newspaper, I have written 14 times about this issue from June 1995 to March 2003.

On May 29, 2003, the Central Disaster Management Council, a Japanese government body, came up with the "General Principles Regarding Countermeasures for the Tokai Earthquake," announcing that they were going to reconsider the countermeasures for Tokai earthquake. Accordingly, revisions were started on "The Basic Plan for Earthquake and Disaster Prevention." This Basic Plan will consolidate the countermeasures at the time of issuing a warning statement with more loosened regulations. These drastic revisions are the first changes to the plans in the last 25 years.

National newspapers reported this shift in policy. Accord- 
Table 4. Nuclear power generation in the world (2001, Dec. 31).

\begin{tabular}{|cc|c|c|c|c|}
\hline & \multicolumn{2}{|c|}{ In operation } & \multicolumn{2}{c|}{ Under construction } \\
\hline & Country & Output (MW) & Number & Output (MW) & Number \\
\hline 1 & U.S.A. & 101,742 & 103 & & \\
\hline 2 & France & 62,920 & 57 & 3,032 & 2 \\
\hline 3 & Japan & 45,082 & 52 & 4,942 & 5 \\
\hline 4 & Russia & 22,556 & 30 & 4,000 & 4 \\
\hline 5 & Germany & 22,355 & 19 & & \\
\hline 6 & Korea & 13,716 & 16 & & \\
\hline 7 & England & 13,531 & 33 & & \\
\hline
\end{tabular}

(Japan Atomic Industrial Forum)

ing to the July 29 Mainichi newspaper, "On July 28, JMA decided to give cautionary information during a preliminary stage before a warning statement, if highly probable precursory phenomena are observed." Another report in a magazine (Shukan Asahi, Aug. 15, 2003) said that the "alert" proposed by Mogi 17 years ago would be finally realized. It is also reported that concrete measures are under consideration and are to be implemented from the beginning of 2004 .

\section{Dangers of Nuclear Power Plants in the Focal Region of the Tokai Earthquake}

Next, I discuss another issue that could potentially bring a critical and man-made disaster to all of Japan. It is the issue of the Hamaoka nuclear power plants that are located near the center of the focal region of the expected Tokai earthquake.

\subsection{Distributions of nuclear power plants and large shallow earthquakes}

Table 4 shows a list of the top seven nations as of January 2002, according to the amount of nuclear power generation (Japan Atomic Industrial Forum, 2002). Almost all of these nuclear power states are advanced nations, with the U.S.A. at the top, followed by France, Japan, Russia, and Germany. We can see from this table, not surprisingly, that the production of the U.S.A., the superpower of the world, overwhelmingly exceeds the others, but Japan, a nation of small islands is third. Also Japan is on the top in regard to the number of nuclear power plants under construction (as of 2002).

There have been vigorous arguments on the safety of nuclear power plants over time under various circumstances. Almost nobody denies the potential catastrophic hazards of nuclear power plants. In fact, this kind of concern unfortunately became a reality with the 1979 Three Mile Island accident on the East Coast of the U.S.A., and the catastrophic 1986 Chernobyl accident in the former USSR. Through these experiences, Germany, the top economic power in the EU, decided to phase out nuclear power, and several other European countries have reconsidered their nuclear power policy much more cautiously.

It is important that we know where all the nuclear power plants are located in the world today. Figure 9 shows the distribution of nuclear power plants in the world, as of year 2000 (Data from the Federation of Electric Power Companies of Japan, 2000). We can see that the distribution is not even, and most of the nuclear power plants are concentrated in the U.S.A., the European region with France as its center, and Japan. These three densely concentrated areas are the top three nuclear power nations.

Figure 10 shows the distribution of large shallow earthquakes of magnitude (M) 7.0 or lager with focal depths less than $40 \mathrm{~km}$ in the past 100 years (Data from Utsu, 2002). One example of a large shallow M 7 class earthquake is the Kobe Japan, earthquake (M 7.3, with maximum Seismic Intensity of 7 on the JMA scale) that occurred directly under the city of Kobe on January 17, 1995. This earthquake caused the Great Hanshin Earthquake Disaster with a death toll amounting to about 6400 and a huge number of collapsed houses, bridges, and highways. An M 8 class earthquake emits energy 30 times greater than that of an M 7 class earthquake. As mentioned before, the expected Tokai earthquake may be a great earthquake of M 8 .

We can see from the distribution of the earthquakes in the world, shown in Fig. 10, that large shallow earthquakes do not occur frequently everywhere, but only in limited regions. One of these regions is the Circum-Pacific Seismic Belt, along the rim of the Pacific ocean, and the other one is the Himalaya-Alps Seismic Belt that connects Java-SumatraBurma-Unnann-Himalaya-Turkey and Greece. One thing to be noted is that there are no such large earthquakes on the European continent and the American continent (except along the Pacific coast). These continents are quite stable. Also, during modern times, there are no major earthquakes in the Korean peninsula.

On the other hand, in Fig. 10, there are many earthquakes in and around the Japanese Islands. The Japanese Islands are completely contained within the Circum-Pacific Seismic Belt, the most active seismic zone in the world, and thus Japan is essentially an unstable area.

Figure 11 shows both the distributions of nuclear power plants and large shallow earthquakes in the same map. In this figure, it can be clearly seen that for the three major nuclear power plant areas, at sites in Europe and the U.S.A., large shallow earthquakes have not occurred recently. In Japan, however, the nuclear power plant sites and the active seismic region are completely in the same areas. In short, unlike in western countries, Japanese nuclear power plants are located in the dynamically unstable areas, which is strongly suggested by the high seismic activity.

As shown in Fig. 11, in the U.S.A., the largest nuclear power in the world, most of the nuclear power pants are located in the east, where the seismic hazards are relatively low. There are a few nuclear plants in the western regions, 


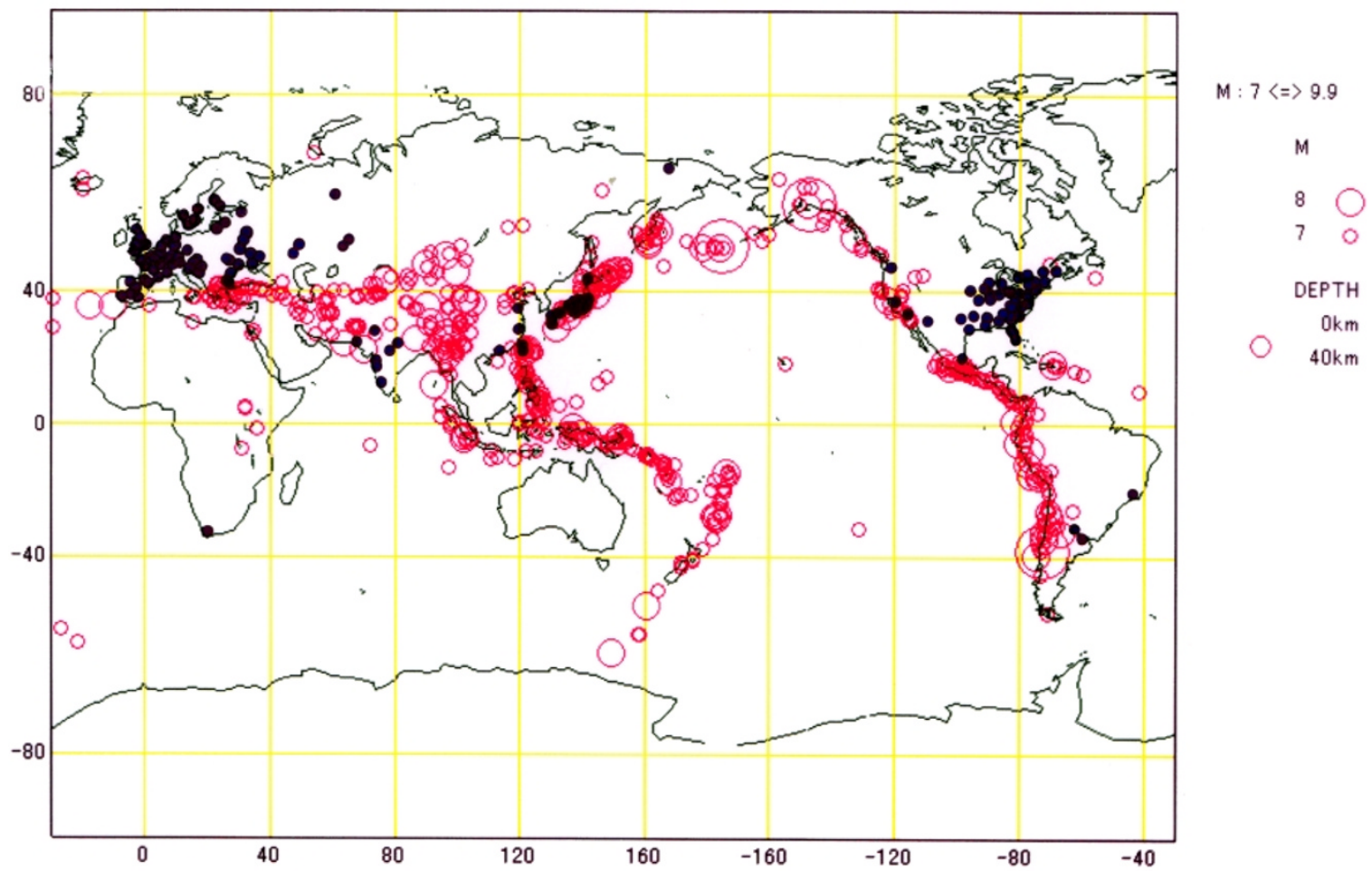

$\mathrm{N}=638$

Fig. 11. Distributions of nuclear power plants (black circle) and large shallow earthquakes in the past 100 years (red circle) are shown on the same map.

\section{Nuclear Power Plants in Japan \\ (Data from Agency for Natural Resources and Energy)}

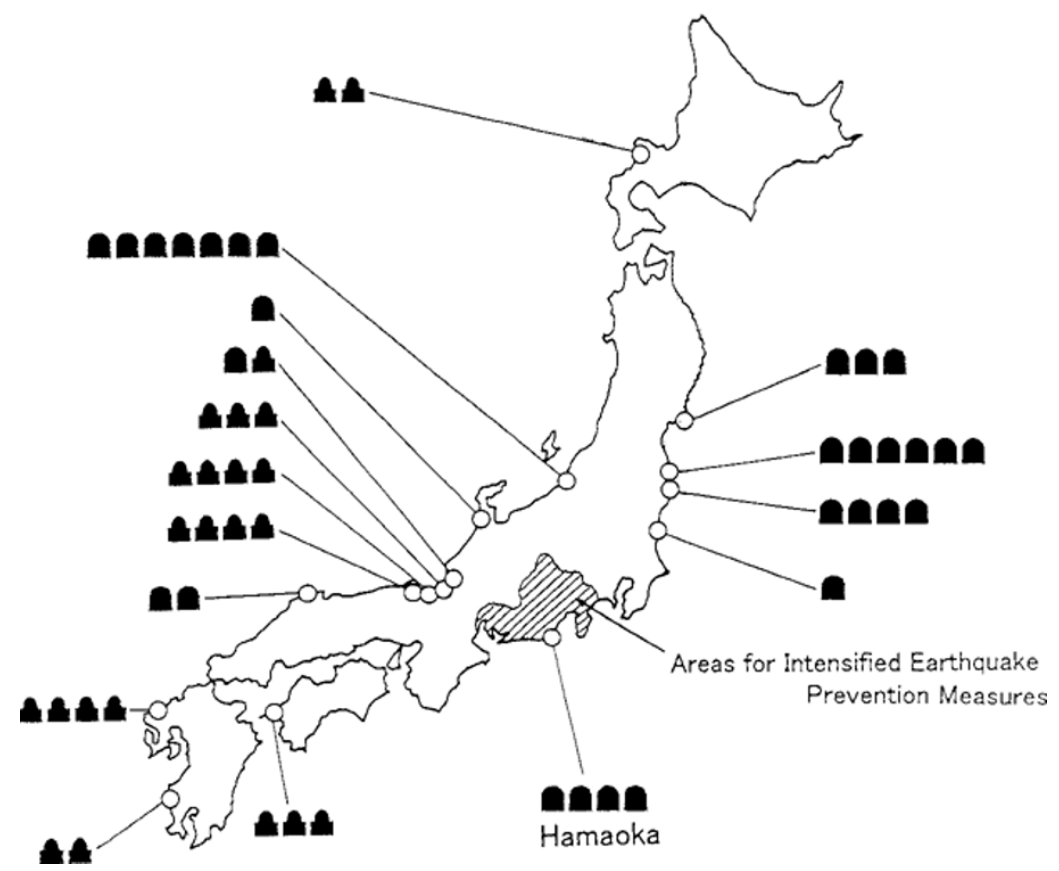

Fig. 12. Locations of nuclear power plants in Japan (Agency of National Resources and Energy, 2002) and Areas for Intensified Earthquake Prevention Measures concerning the expected Tokai earthquake (Central Disaster Management Council, 2002). 


\section{Hamaoka Nuclear Power Plants Unit 1 4}

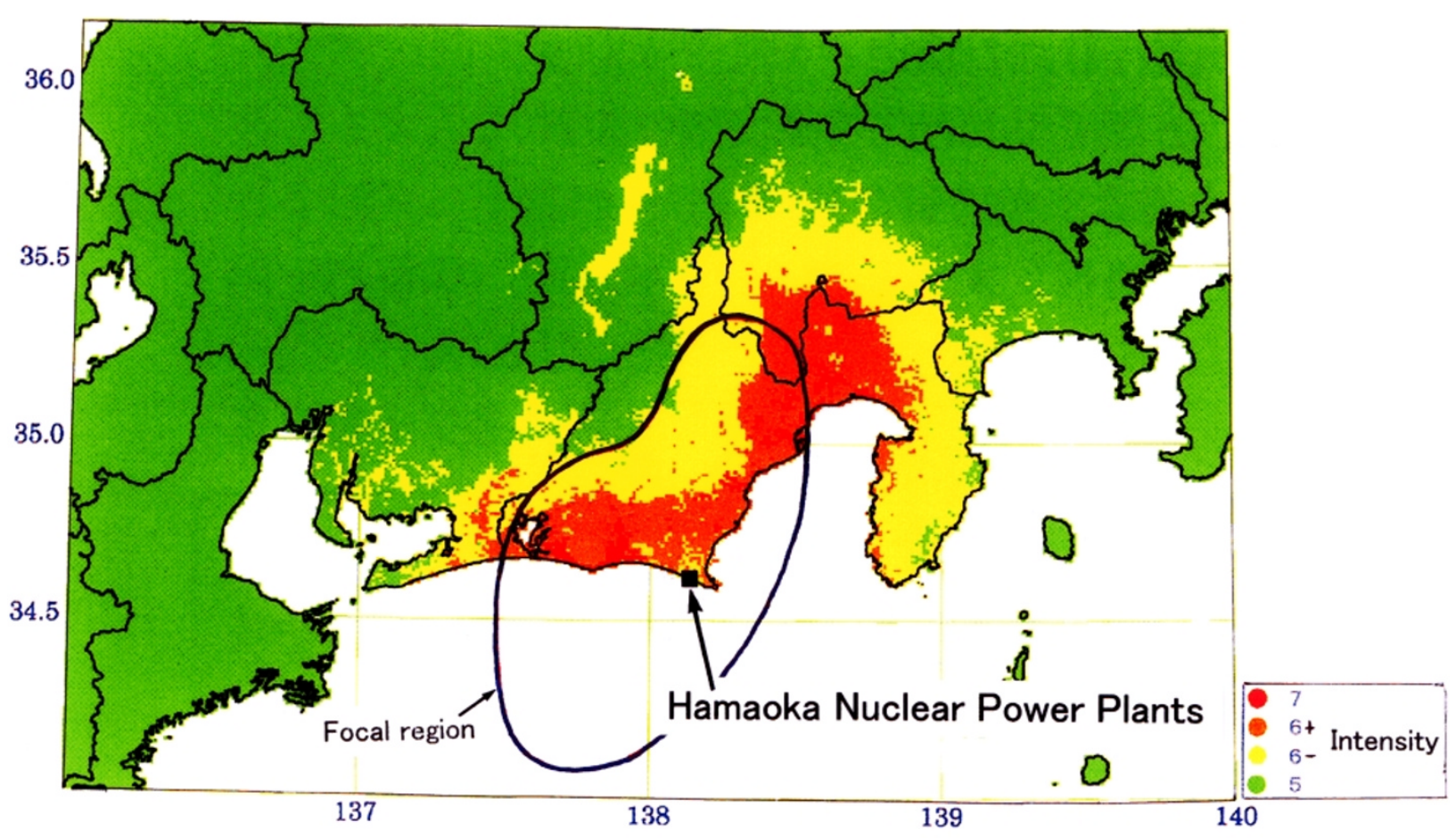

Central Disaster Management Council

Fig. 13. Focal region of the expected Tokai earthquake and the Hamaoka nuclear power plants (Unit 1 4).

where damaging earthquakes have occurred, for example the 1906 San Francisco earthquake (Mw 7.8) and the recent 1994 Northridge earthquake (Mw 6.7) near Los Angeles. The sitting of all these nuclear power plants has undergone extensive (and sometimes controversial) seismic hazard evaluations.

France, the second largest nuclear power plant country, has hardly had any significant earthquakes and its land is quite stable.

\subsection{Problems of the locations of the Hamaoka nuclear power plants}

Generally speaking, in cases where nuclear power plants are constructed, sitting needs to be carefully considered so that dangers caused by earthquakes would be averted as much as possible. However, as mentioned above, the Japanese Islands are located in the very active seismic zone, where the Pacific plate is moving toward the northwest, colliding with the Asian continental plate and subducting below.

Figure 12 shows the location of Japanese nuclear power plants prepared from materials published by the Agency for National Resources and Energy (2002). As mentioned above, all of the Japanese Islands are within the active seismic region, but only the Tokai region is an area where an $\mathrm{M}$ 8 class earthquake is predicted to occur in the near future. As mentioned in the previous section, the government acknowledged the urgency for this area, and enacted the Large-Scale Earthquake Countermeasures Law.

As mentioned before, the focal region is predicted and the areas where the high seismic intensity is expected are specified as "Areas for Intensified Earthquake Prevention Measures". It is truly a grave problem that the Hamaoka nuclear power plants have been built and put into operation very near the center of the predicted focal region. Thus, the Hamaoka nuclear power plants are located in the one area that should have been avoided from the viewpoint of earthquake prediction research in the Japanese Islands, as pointed out by some researchers (e.g. Komura, 1981; Ishibashi, 1997; Mogi, 2001c). Figure 13 shows the enlarged map of the area, and the curved line shows the predicted focal region, with the Hamaoka nuclear power plants near the center.

It is quite important to know whether or not the possibility of the "Tokai earthquake" had already been pointed out at the time of construction of the Hamaoka nuclear power plants. From this, we can see how much consideration was given to nuclear safety by the Chubu Electric Company and the government that gave the authorization.

As mentioned before, it was on October 28, 1969 that I pointed out the possibility of an M 8 class earthquake in the Tokai region at the monthly meeting of the Earthquake Research Institute, University of Tokyo, which was open to the public including the media.

The Coordinating Committee for Earthquake Prediction (CCEP) that had just been inaugurated in 1969 asked me to attend the regular meeting of CCEP in November the same year (I was not a member of the Committee at that time), and I made the explanation regarding the possibility of the Tokai 
Table 5. Tokai Earthquake Problem and Hamaoka Nuclear Power Plants.

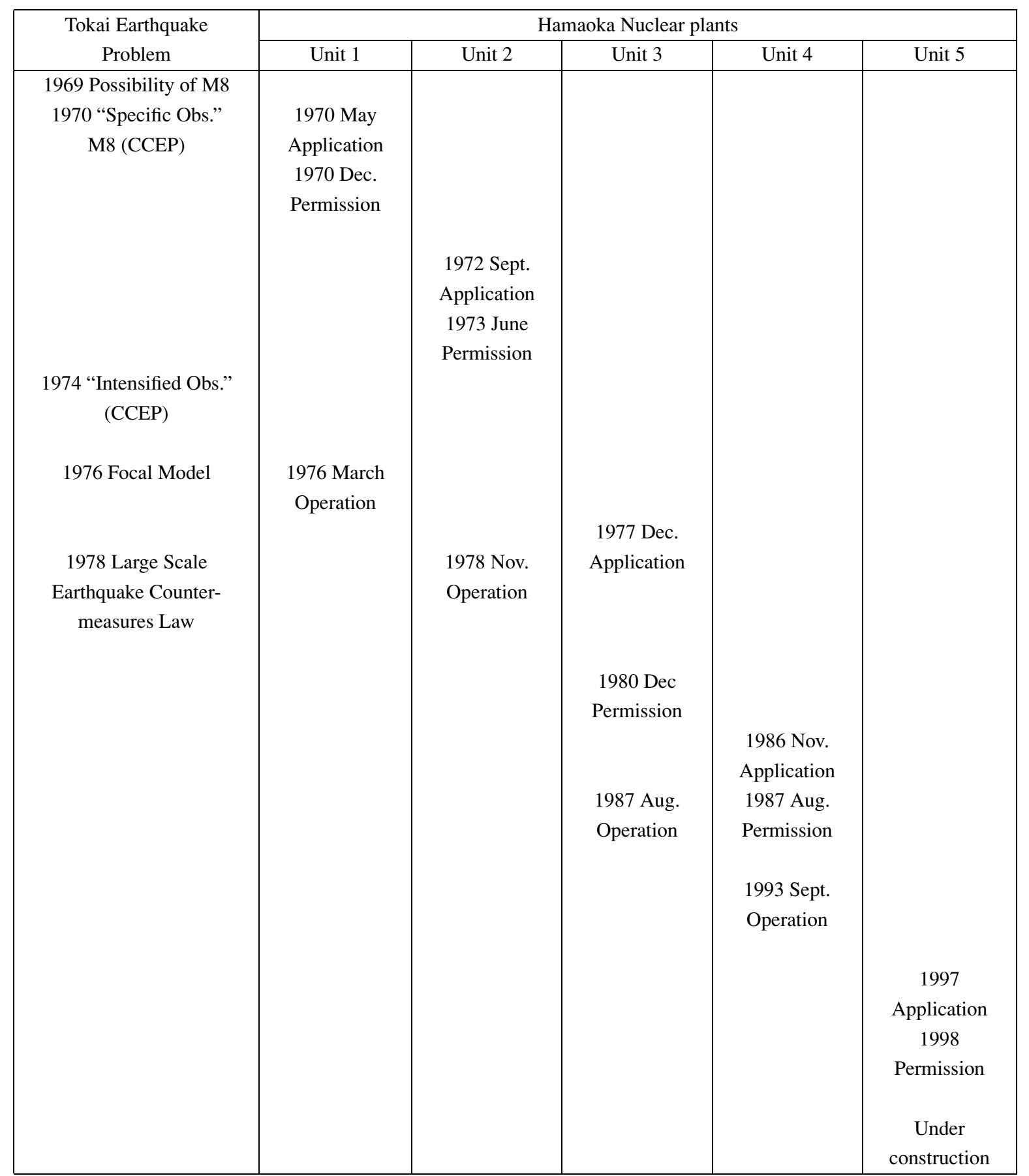

earthquake. After the meeting, this result was announced by Takahiro Hagiwara (Chairman of CCEP) at a press interview. This announcement was immediately reported by newspapers (Asahi, Mainichi, Sankei, and Chunichi), TV (NHK, Fuji, Tokyo) and weekly magazines (Shukan Shincho, Shukan Gendai). The graveness of the issue was acknowledged and after the discussion in the subcommittee on February 6 and at the 6th meeting of the CCEP on February 201970 , it was deduced that the Tokai region would be an Area of Specific Observation for an M 8 class earthquake. This result was extensively covered by the Report of the CCEP (vol. 3) in July the same year.

Since the above-mentioned report in 1969, various inves- tigations and observations on the Tokai earthquake started. For example, Hagiwara himself started to investigate the Seismic Intensity distribution of the 1854 Ansei-Tokai earthquake on the basis of historical documents, and this result was published in the Report of the CCEP in 1970 (Hagiwara, 1970). According to his research, a large area from the northwestern inland side of Suruga Bay to the coastal region of Enshu-nada was hit by Seismic Intensity 7. GSI $(1970,1974)$ examined the results of the leveling surveys, and they reported not only the horizontal crustal movement but also marked vertical movement (subsidence). These crustal movements showed that the stress in the crust had accumulated appreciably. Based on the results from numerous 
investigations, in 1974, CCEP specified the Tokai area as an Area of Intensified Observation, where observations should be increased further due to the high possibility of an earthquake occurrence, and this prompted further precautions.

It was on May 22, 1970, seven months after the announcement of the possibility of the "Tokai earthquake", when Chubu Electric Company applied for the construction of a nuclear power plant at Hamaoka, in the center of the Tokai region. After the examination by the Atomic Energy Commission (AEC), this application was approved by the Prime Minister on December 10, 1970. Hamaoka Unit 1 went into commercial operation in March 1976. In September 1972, Chubu Electric Company submitted the application for Hamaoka Unit 2 and it was approved in May 1973, and its commercial operation started in November 1978 (see Table 5).

While the possibility of the Tokai earthquake was being pointed out, and surveys and observations were started, the problem was also getting social attention. Hamaoka nuclear power plants were proposed, and were licensed during only a several month period of examination by the Atomic Energy Commission. I cannot help being doubtful about how much they were aware of the fact that the sitting of nuclear power plant is fundamentally important to avoid nuclear disaster. The information from seismology is always progressing, and it would have been appropriate to stop and reconsider the sitting, based on new research results about the Tokai region. However, in fact, the series of movements by the CCEP were totally overlooked, and Hamaoka Units 1 and 2 were proposed and licensed in a very short time period, and the construction went underway. It was regretful that I was not even notified about the construction of such nuclear power plants.

The left column of Table 5 shows the chronological progress of the measures for disaster mitigation of the "Tokai earthquake". For comparison, the right columns show the year and month of the application and operation of Hamaoka Units 1 to 4, with addition of the construction of Unit 5 . When we take a look at this, while on one hand, a unique law which is the first of this kind in the world was established saying, "Let's predict the Tokai earthquake and mitigate the disaster by implementing various measures", while on the other hand, nuclear power plants were being built one after another in Hamaoka, located near the center of the expected focal region. It is not meaningful to simply say that no nuclear power plants should be built in any area that has the potential for a large earthquake, especially since there is a chance (although it may be small) of a large earthquake in practically any land region. However, practical decisions should be made with appropriate consideration of the risks involved, especially for an area that has a very high chance of a large earthquake during the lifetime of the nuclear facility.

\subsection{Dangers of Hamaoka nuclear power plant}

As mentioned in 3.1, in regard to the safety of nuclear power plant, there have been vigorous arguments from the early stages. In fact, larger scale accidents have happened in the past, so there is almost nobody who would deny the large potential risk of nuclear power plants (e.g. Nakajima, 1984). However, discussions about nuclear power plant safety is- sues in western countries are being done in places where there are very few large earthquakes. Sitting of nuclear power plants outside of Japan has usually been chsoen in areas that have low probabilities of large earthquakes. For safety considerations, regions of high seismic hazard have been rejected as sites for nuclear power facilities.

In order to build a nuclear power plant, there are examinations at Nuclear Safety Commission. The Hamaoka nuclear power plant was also examined, and based on the Commission's response, the Prime Minister authorized the license. In any case, the recommendation of the Commission itself would have a big influence on this licensing process. I pointed out the possibility of Tokai earthquake for the first time, and then worked for 10 years as the chairman of the Committee of the "Area of Intensified Observation" (Tokai and Tokyo Metropolitan areas) in CCEP. From 1978, I was a member of the Earthquake Assessment Committee (EAC) for the Tokai earthquake since it was inaugurated for predicting the Tokai earthquake based on the Large-Scale Earthquake Countermeasure Act, and eventually became the chairman of EAC in 1991. Probably, I should have been one of the most closely working members regarding the Tokai earthquake issue. However, though I have been involved with this issue for more than 30 years, I have never been asked about the sitting and safety issue of the Hamaoka nuclear power plants by either the government or the Chubu Electric Company, officially or unofficially. It is fair to state that to my knowledge, the impact of the predicted "Tokai earthquake" was not properly included in the sitting decisions for the Hamaoka nuclear power plants.

A nuclear power plant is a complex facility. It contains not only the reactor itself, but also has various buildings with countless numbers of pipes and conduits. The safety of such a compound facility is complex with many vulnerable points, and thus unexpected damage may occur. Also, there are many unknown aspects of the ground conditions which supports a nuclear power plant, and the ground behaviors is complex when any stress is applied. Moreover, assuming that the magnitude and general location of an earthquake could be predicted, there still is very limited knowledge regarding the shape of the fault plane and its rupture process. Presently calculated scenarios contain only limited simulations, and these can be quite different from reality. In short, there are many uncertainties regarding the evaluations of safety for nuclear power plant related to the occurrence of an expected great earthquake.

Each time a large earthquake occurs, there have been new types of damage beyond our expectations, and the earthquake resistance criteria, such as the Building Standard Law of Japan, have been revised. When they saw highways falling one after another at the time of the 1994 Northridge, California earthquake, Japanese earthquake engineers said publicly, "These things will never happen in Japan". However, just one year later in 1995, they saw a highway collapse caused by the Kobe earthquake, and "Japan's safety myth" was destroyed.

In 2003, the M 7 (not so large) Miyagiken-oki earthquake occurred, in northeast Japan, with a relatively deep focal depth $(70 \mathrm{~km})$ and caused considerable damage to bridge columns of the Tohoku bullet train railway that had recently 
been built. There are always the possibilities of unexpected accidents and destruction even though we carry out good planning efforts. There is nobody who can say that nuclear power plants will be safe when a great M 8 shallow earthquake occurs just below the sites.

If a highway bridge is destroyed by an earthquake, it would be a problem, but still only a limited one. However, if there were a large accident in Hamaoka, the impact would not be limited to just the local area, but would affect a wide area in Honshu, including Tokyo and Nagoya. This is such a grave issue, and if such a thing happened, we cannot simply say, “This was unexpected". NHK news programs and some newspapers covered the news of a recent pipe explosion accident at the Hamaoka nuclear power plant. Topics relevant to the Tokai Earthquake problem such as revision of the Intensified Area, are also attracted media's attention. However, why is there hardly any news pointing out the importance of this issue when simply considering the fact that the Hamaoka nuclear power plants are located near the center of the focal region of the expected great Tokai earthquake?

As I mentioned so far, the issue of the Hamaoka nuclear power plants and the Tokai earthquake is a critical problem which can bring a catastrophe to Japan through a man-made disaster. At the same time, this is a problem we human beings can prevent. Can nuclear power plants located just above the focal region withstand a great shallow earthquake? Japan, the sole country exposed to atomic bombs, should not conduct such an experiment, which no other country would dare.

\section{Concluding Remark}

Large earthquakes occur unexpectedly in most cases and sometimes inflict enormous damage. Earthquake prediction, which may contribute to mitigation of earthquake disasters, is not only an extremely fascinating subject in seismology, but also its ultimate goal. However, earthquake prediction problems go beyond the bounds of merely being a specialist subject in one area of natural sciences. In this paper, two serious issues are discussed concerning the expected Tokai earthquake (M 8), central Honshu, (1) the danger of blackand-white predictions and (2) the danger of nuclear power plants constructed at Hamaoka, near the center of the expected focal region of the Tokai earthquake. These issues may cause catastrophes for Japanese society. It is important to explore these problems more thoroughly in order to proceed with the most suitable measures given current realities.

Acknowledgments. I am greatly indebted to Prof. Mori James Jiro for his help during the preparation of the manuscript. I would like to thank Drs. Keiiti Aki, David Simpson and two anonymous reviewers for their comments on this manuscript.

\section{References}

Agency of Natural Resources and Energy, Sites of nuclear power plants in
Japan, pp. 26, 2002 (in Japanese).

Central Disaster Management Council, Report on the Tokai Earthquake by Organization for Technical Investigation in Central Disaster Management Council in 2001, 2001.

Central Disaster Management Council, Report on the Tokai Earthquake by Organization for Technical Investigation in Central Disaster Management Council in 2002, 2002.

Coordinating Committee for Earthquake Prediction, Designation of Areas of Specific Observation, Report of Coordinating Committee for earthquake Prediction, 3, 89-91, 1970.

Federation of Electric Power Companies of Japan, Home page from FEPC, www.fepc-atomic.jp, 2000.

Geographical Survey Institute, Japan, Vertical movements in Tokai district, Report of Coordinating Committee for Earthquake Prediction, 2, 49-53, 1970 (in Japanese).

Geographical Survey Institute, Japan, Vertical movements in Tokai district (2), Report of Coordination Committee, 11, 102-104, 1974 (in Japanese). Geographical Survey Institute, Japan, Horizontal displacements observed by GPS (1998-1999) in and around the Tokai region, personal communication, 2003.

Hagiwara, T., Distribution of Seismic Intensity in 1854 Tokai earthquake, Report of Coordinating Committee for Earthquake Prediction, 3, 51-52, 1970 (in Japanese).

Harada, K. and N. Isawa, Horizontal deformation of the crust in JapanResult obtained by multiple fixed stations, J. Geodetic Soc. Japan, 14, $101-105,1969$.

Ishibashi, K., Re-examination of a great earthquake expected in the Tokai district: Possibility of the 'Suruga Bay earthquake', Abstracts, Seismol. Soc. Japan 1976, No. 2, 30-34, 1976 (in Japanese).

Ishibashi, K., Genpatsu-shinsai, Kagaku, 67, 720-724, 1997 (in Japanese). Japan Atomic Industrial Forum, Generating capacity of nuclear power plants in the world, Nuclear Power Plants in the World, Tokyo, 195 pp, 2002.

Kasahara, K. and A. Sugimura, Spatial distribution of horizontal secular strain in Japan, J. Geodedic Soc. Japan, 10, 139-145, 1964.

Komura, H., Tokai earthquake and Hamaoka nuclear power plants, Kagaku, 51, 449-457, 1981 (in Japanese).

Land Agency, Earthquake Countermeasures in Japan, 1987.

Mogi, K., Recent horizontal deformation of the earth's crust and tectonic activity in Japan (1), Bull. Earthq. Res. Inst., Univ. of Tokyo, 48, 413430; Seismological interpretation of recent horizontal deformation of the earth's crust in western Japan, Report of Coordinating Committee for Earthquake prediction, 2, 85-88, 1970 (in Japanese).

Mogi, K., Temporal variation of crustal deformation during the days preceding a thrust-type great earthquake-The 1944 Tonankai earthquake of magnitude 8.1, Japan, Pageoph, 122, 765-780, 1985.

Mogi, K., Earthquake prediction problem in the Tokai region, Proc. of Earthquake Prediction Research Symposium, 279-284, National Committee for Seismology, Science Council of Japan and Seismological Soc. of Japan, 1987 (in Japanese).

Mogi, K., Need of reexamination of the Tokai earthquake countermeasure, This is Yomiuri, Oct. 1996, 68-77, 1996 (in Japanese).

Mogi, K., Reexamination of the Tokai earthquake countermeasure, Zisin Journal, 32, 1-7, 2001a (in Japanese).

Mogi, K., Zishin no Hanashi (Stories of Earthquakes), Tokyo, Asakura Shoten, 150 pp, $2001 b$ (in Japanese).

Mogi, K., Hamaoka nuclear power accident and earthquakes, Rondan, Nov. 13, 2001, Shizuoka Shinbun, 2001c (in Japanese).

Nakajima, T., Arguments for and against the nuclear power generation, Heibonsha Encyclopedia, 5, 117-122, 1984 (in Japanese).

Utsu, T., Seismicity Studies: A Comprehensive Review, Tokyo, 876 pp (see page 791), Univ. of Tokyo Press, 1999 (in Japanese).

Utsu, T., Catalog of Damaging Earthquakes in the World (through 2002), http://iisee.kenken.go.jp/utsu/index_eng, 2002.

Working Group on California Earthquake Probabilities, Seismic hazards in Southern California: Probable earthquakes, 1994-2024, Bull. Seismol. Soc. Am., 85, 379-439, 1995. 